\title{
LITERATURA SURDA: CONTRIBUIÇÕES LINGUÍSTICAS PARA ALUNOS SURDOS, OS SUJEITOS DA EXPERIÊNCIA VISUAL NA ÁREA DA EDUCAÇÃO
}

Carilissa Dall'Alba*

Marianne Stumpf**

\begin{abstract}
Resumo: O trabalho trata das contribuições da literatura surda para a educação de surdos em uma perspectiva bilíngue. O surdo constrói os seus significados por meio da experiência visual que perpassa a cultura surda. A circulação de literatura surda - uma das marcas culturais surdas - na educação de surdos colabora com a constituição de identidades surdas. Para a realização deste artigo foi necessário fazer pesquisas bibliográficas dos autores da área de educação de surdos com atravessamentos do campo de literatura surda e da literatura clássica, da qual foram feitas adaptações. A pesquisa foi desenvolvida com base no material existente, constituído principalmente de livros e artigos científicos. Foi feito um breve levantamento das obras publicadas no país, principalmente na literatura infantil.
\end{abstract}

Palavras-chave: Educação de surdos. Literatura surda. Cultura surda. Tecnologia.

Abstract: The paper deals with the contributions of the deaf literature to the education of the deaf in a bilingual perspective. The deaf construct their meanings through visual experience that pervades the deaf culture. The circulation of deaf literature in the education of the deaf helps the constitution of deaf identities. For the accomplishment of this article it was necessary to carry on a research about the authors of the area of education of deaf people in conjunction with the field of deaf and classic literature, of which adaptations were made. The research was developed based on existing materials, consisting mainly of books and scientific articles. A brief survey of works published in Brazil was performed, mainly in children's literature.

Keywords: Deaf education. Deaf literature. Deaf culture. Technology.

\section{Histórico sobre línguas de sinais na educação dos surdos}

Através dos tempos a história dos surdos foi marcada por conflitos e rupturas. Muitos embates foram travados, para que hoje os surdos pudessem estar incluídos no contexto educacional. Na história dos surdos temos registros de surdos e as reações dos ouvintes em relação aos mesmos. Podemos citar como exemplos a Grécia e a Itália, locais em que os surdos eram privados de quaisquer direitos e também eram tratados como animais. Em contrapartida, no Egito eles eram considerados pessoas especialmente escolhidas, o que lhes dava um status místico. Avançando no tempo, contamos com a aparecimento de Pedro Ponce De Leon, um monge que fazia uso do alfabeto manual. Foi o precursor em ensino da Língua de Sinais e comprovou ao rei e aos nobres que esses sujeitos eram possíveis de serem ensinados. Há relatos da existência de um número grande de professores surdos na idade antiga. Segundo Sacks (1989, p. 32), em 1869, havia 550 professores de surdos em todo o mundo e que $41 \%$ desses professores nos Estados Unidos eram eles próprios, surdos. Existem vários personagens que foram importantes na área da educação de surdos, dentre os principais podemos citar Juan Bonet, Jacob Rodrigues Pereire, Johann Conrad Amman, John Wallis, Thomas Braidwood e Eduard Huet.

A primeira escola para surdos no Brasil foi fundada em 1857 no Rio de Janeiro/RJ e certamente foram criados vários materiais visuais que colaboraram para uma educação de qualidade aos surdos do século XIX. A primeira escola para surdos do Brasil se chama de

\footnotetext{
* Aluna do Curso de Doutorado da Universidade Federal de Santa Catarina (UFSC). Endereço eletrônico: carilissa27@gmail.com

** Professora da Universidade Federal de Santa Catarina. (UFSC). Endereço eletrônico: stumpfmarianne@gmail.com
} 
Instituto Nacional de Educação de Surdos (INES). Felizmente temos o registro de umas imagens do primeiro livro de sinais do Brasil, do autor Flausino José da Gama, em 1875, registros de sinais com influência de Língua de Sinais Francesa (LSF), já que INES foi fundada por um professor surdo francês, Eduard Huet, que foi professor do Flausino, também surdo. O livro foi impresso, mas só continha desenhos de sinais, um recurso visual utilizado na época. O livro se chamava de Iconographia dos Signaes dos Surdos-Mudos.

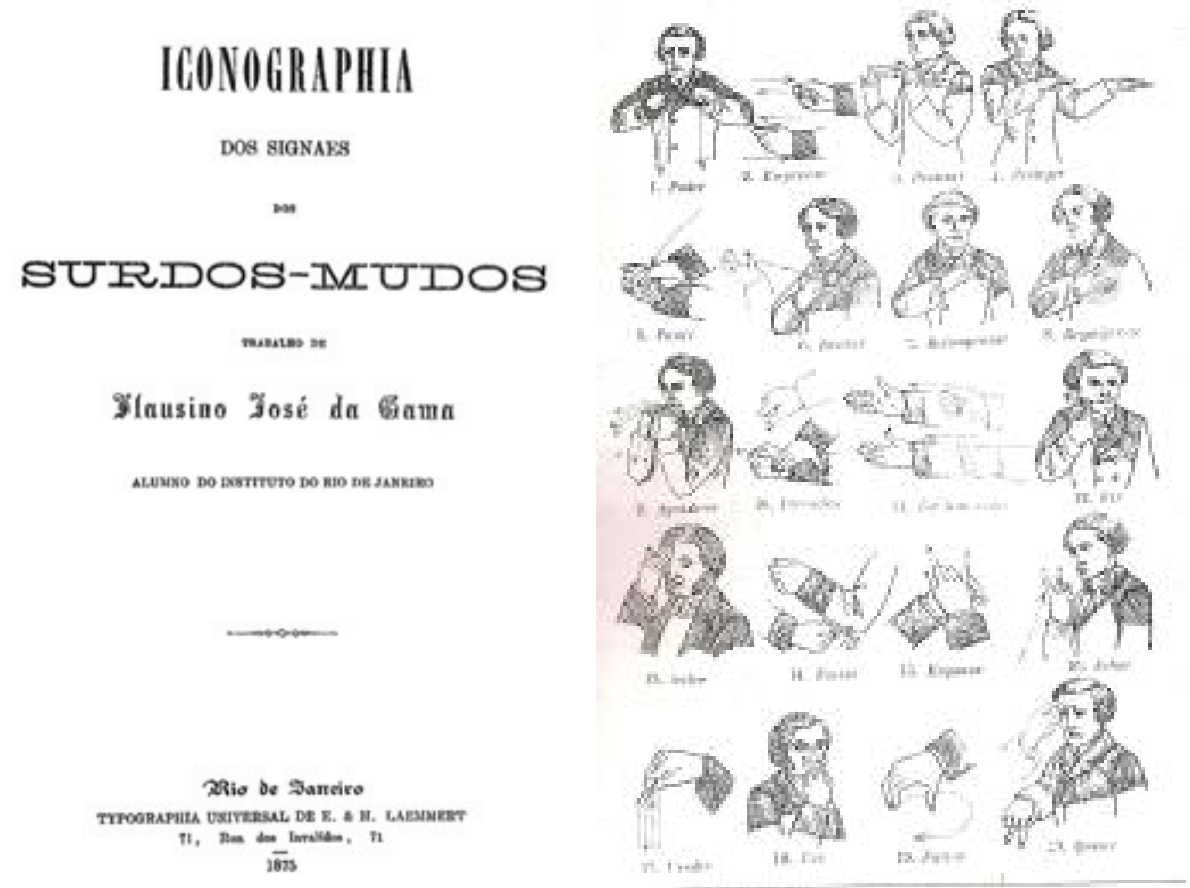

Figura 1 - O livro Iconographia dos signaes dos surdos-mudos Fonte: Editora Arara Azul.

Houve um desmerecimento da cultura surda e de sua língua por volta de 1880 , no Congresso de Milão, evento esse em que os surdos foram proibidos de usar sua primeira língua, pois os ouvintes acreditavam que ela atrapalhava o ensino dos surdos que, segundo eles, deveriam aprender a falar. Tal proibição acabou sendo estendida a outras escolas em outros países.

No início da década de 1970, após estudos linguísticos que provaram que as línguas de sinais eram línguas completas, elas voltaram a ser utilizadas na educação de surdos e começou um processo de autonomia dos sujeitos surdos. No Brasil também houve estudos que mostraram que a Língua Brasileira de Sinais - a Libras - assim como as línguas orais, possui todos os níveis linguísticos: fonológico, morfológico, sintático, semântico e pragmático. Conforme Quadros e Karnopp (2004):

As línguas de sinais são, portanto, consideradas pela linguística como línguas naturais ou como um sistema linguístico legítimo e não como um problema do surdo ou como uma patologia da linguagem. Stokoe, em 1960, percebeu e comprovou que a língua dos sinais atendia a todos os critérios linguísticos de uma língua genuína, no léxico, na sintaxe e na capacidade de gerar uma quantidade infinita de sentenças [...] observou que os sinais não eram imagens, mas símbolos abstratos complexos, com uma complexa estrutura interior. Ele foi o primeiro, portanto, a procurar uma estrutura, a analisar os sinais, dissecá-los e a pesquisar suas partes constituintes. (QUADROS; KARNOPP, 2004, p. 30). 
Por meio de estudos realizados em vários países, foi comprovado que as línguas de sinais são completas e a partir disso elas começaram a ser consideradas como primeira língua do surdo, sendo reconhecidas oficialmente em muitos países. Esse foi um marco na história da educação dos surdos, pois os sinais voltaram a ser utilizados nas escolas.

\section{Metodologia}

A minha experiência de trabalhar com a literatura surda com alunos surdos começou na Escola de Surdos Helen Keller ${ }^{1}$. Nas aulas de Português e Libras eu oferecia livros de literatura surda e percebi que os alunos que estudavam na escola desde crianças empoderaram-se mais ao conhecer a literatura surda. Já os alunos que adquiriram a Libras tardiamente tinham mais dificuldades de aprendizagem. Conhecer a Libras o mais cedo possível é essencial para educação de surdos. Por isso é muito importante ter um estímulo precoce na língua de sinais, a primeira língua dos surdos. Nessa escola a língua de instrução é a Libras e o Português é a segunda língua, na modalidade escrita. As aulas são planejadas pensando na experiência visual e a literatura surda é grande aliada no ensino de Libras aos alunos surdos. Os livros de literatura surda têm Libras e personagens surdos, desta forma os surdos conseguem ter um aprendizado mais amplo, já que o acesso à literatura é um direito humano. Além da pesquisa bibliográfica de autores da área de educação de surdos, a pesquisa foi desenvolvida com base em publicações de obras de literatura surda.

\section{Cultura surda}

A temática da literatura surda é muito importante por fazer parte da cultura surda. A cultura surda pode ser entendida como a maneira de o surdo interpretar o mundo por meio da experiência visual, ou seja, a partir dessa experiência utilizamos no cotidiano artefatos visuais, fotos, vídeos e obras produzidas pelos sujeitos surdos. A primeira língua dos surdos, a língua de sinais, é o elemento principal da cultura surda e se faz muito presente na literatura surda.

Em 1960, o pesquisador americano William Stokoe afirmou que a língua de sinais é uma língua, e não uma linguagem, ele também revolucionou o campo de estudos da área de linguística nos anos 1960, já que naquela época só havia pesquisas sobre línguas orais, ou seja, línguas faladas. Mostrou ao mundo linguístico que as línguas de sinais têm estruturas e funções semelhantes às línguas faladas. "[...] a língua de sinais dos surdos tem estrutura e função semelhante às demais línguas" (STOKOE, 1960, p. 3). Cada país tem a sua língua de sinais, assim como acontece com as línguas orais, por isso não existe uma língua de sinais.

Dentro do universo linguístico dos surdos, existe a literatura surda, que é diferente da literatura da língua falada, pois é a visualidade que possibilita a existência de literatura surda como uma representação dos sujeitos surdos. Segundo Mourão (2011):

Não é fácil definir a Literatura Surda. Assim como não há uma única conceituação para literatura geral, também não há uma definição única para Literatura Surda. Quando se fala nela, especificamente, vemos que está relacionada às representações produzidas por surdos, em que se produzem significados partilhados em forma de discurso - sem eles, não há representação surda. Os significados são modificados dentro do círculo da

\footnotetext{
${ }^{1}$ A Escola Estadual Especial de Ensino Médio Helen Keller foi fundada há 57 anos em Caxias do Sul - RS e trabalha com alunos surdos. Todos os professores, inclusive os ouvintes, utilizam Libras.
} 
cultura, e o sujeito não cria sozinho a cultura, já que sempre há o coletivo produzindo significados. (MOURÃO, 2011, p. 73).

Como explica Mourão, não há uma única conceituação para a literatura geral, por isso não há um único conceito para a literatura surda. Por isso não é fácil definir a literatura surda. Ocorreram mudanças ao longo dos tempos que hoje nos possibilitam pensar sobre os processos de transformações que vêm ressignificando a língua de sinais dentro da literatura surda. $\mathrm{O}$ que podemos ressaltar é que ela se articula com a língua de sinais e com o mundo surdo, ou seja, é uma forma de arte articulada com a língua de sinais que resultam nas produções de obras literárias, tanto como poesias, contos, teatro e traduções de outras obras, mas vinculadas à língua de sinais. Os livros de literatura surda são considerados artefatos culturais, pois além do caráter informativo, eles ajudam a construir a identidade desses sujeitos. Para entendermos melhor, basta pensarmos que na aquisição da linguagem de crianças surdas é fundamental o contato com esses materiais para que elas possam se identificar com elementos de sua cultura e assim aprender sua primeira língua - Libras.

O artefato cultural dos Surdos é organizado de acordo com a visualidade e utiliza uma estratégia para substituir a ausência do som. Pela ausência do som, criamos as nossas informações sobre cultura do seu criador em detrimento da maioria da comunidade surda e seus usuários que perderam ou nunca tiveram contato com a Língua de Sinais. O artefato varia e é acrescido ao longo do tempo, dependendo da evolução da tecnologia, de novas descobertas e dos recursos que nós necessitamos para viver por meio da visão. E destes criam-se um pertencimento cultural que, por meio da visualidade, se apropria, se media e transmite a cultura proporcionando vários significados capazes de promover a sociabilidade e a identidade através da visualidade e da "experiência visual" como protagonistas dos processos culturais da comunidade surda. (CAMPELLO, 2008, p. 91).

A literatura surda é uma das marcas da cultura surda, bem como a exaltação da diferença surda e a identidade surda combativa, que traz em si um forte traço de oposição entre surdos e ouvintes e organiza o movimento dos surdos por direito a legendas em filmes brasileiros e a presença de intérpretes em vários lugares. Outra marca é a vida dentro da comunidade surda, constituída também por ouvintes - professores, intérpretes e familiares que dominam a língua de sinais (LOPES, 2007).

A noção de comunidade surda é atravessada pela experiência visual e mediada pela língua de sinais. A comunidade surda é, para seus integrantes, um lugar seguro onde todos partilham de códigos semelhantes. Nesse espaço que não é geográfico não há necessidade de ILS, não há disputa de poder com ouvintes. Em muitas cidades há um local onde os surdos se encontram para conversar em sua língua. A maioria dos surdos se relaciona emocionalmente com surdos. Parentes, ILS e amigos de surdos frequentam as associações. Para muitos surdos a comunidade é um porto seguro onde a surdez pode ser narrada através de um outro lugar (FORMOZO, 2008, p. 42).

A cultura surda está dentro de cada pessoa que faz parte da comunidade surda e não se resume somente a materiais visuais, cada um tem um modo de vivenciar a cultura surda e tem um olhar próprio, sua própria maneira de vivenciar a experiência visual, e no conjunto de experiências visuais essa cultura vai se fortalecendo. Bauman (2003) afirma que a comunidade, em um primeiro entendimento, remete a um lugar aconchegante onde seremos acolhidos, compreendidos e confortados quando estivermos em apuros. Estaremos em um 
lugar onde todos se parecem conosco e onde todos se querem bem, onde há amizade, cumplicidade e sentimento de pertencimento. É na comunidade surda que são produzidas as identidades surdas, portanto, cultura e comunidade surda estão relacionadas, uma está presente na outra.

Uma vez que a cultura é o que possibilita a criação de espaços em que as pessoas podem se sentir 'seguras' e 'em casa', a Cultura Surda é mais do que um ajuntamento de ideias, narrativas e materiais. Ela é fundamentada na diferença que funciona como recurso (KARNOPP; KLEIN; LUNARNDILAZZARIN, 2011, p. 28).

A cultura surda é importante para as pessoas surdas, principalmente no que se refere à construção de identidades. $\mathrm{O}$ espaço dos encontros surdos intensifica os laços culturais. Segundo Gomes (2011, p. 131), "saliento esse espaço porque é nele onde muitos surdos começam a se 'ver' surdos, a 'abrir as suas gavetas' de culturas, onde são narrados, se narram, se constituem e são inventados".

A inserção do termo cultura surda nas discussões acadêmicas é imensa. Gomes (2011) afirma que cultura surda é um termo "caro" por ser uma "verdade" absoluta na comunidade surda. A cultura surda abrange toda área de arte e os artefatos de cultura surda, são representados por obras de arte, peças de teatro, literatura, narrativa de histórias, poesia, pintura, teatro, fotografia, cinema e música, tudo articulado com a literatura surda. Os surdos exploram os elementos visuais nas produções artísticas, educacionais e culturais e a literatura surda é reconhecida como uma forma de produção artística.

Os surdos são sujeitos da experiência visual. Segundo a autora surda Karin Strobel (2008, p. 39), "Os sujeitos surdos, com a sua ausência de audição e do som, percebem o mundo através de seus olhos, tudo o que ocorre ao redor dele [...]". E complementam essa ideia os autores surdos Perlin e Miranda (2003):

Experiência visual significa a utilização da visão, em (substituição total à audição), como meio de comunicação. Desta experiência visual surge a Cultura Surda representada pela língua de sinais, pelo modo diferente de ser, de se expressar, de conhecer o mundo, de entrar nas artes, no conhecimento científico e acadêmico. A Cultura Surda comporta a língua de sinais, a necessidade do intérprete, de tecnologia de leitura. (PERLIN; MIRANDA, 2003, p. 218).

A visão é o meio de comunicação mais representado para pessoas surdas. A "experiência visual" também é um "espaço de produção" (QUADROS, 1997). Com as experiências visuais, as produções são ricas em cores e formas, visto que os sujeitos surdos imaginam como seria o mundo em língua de sinais, ou seja, eles traduzem o mundo para a língua de sinais. Isso significa que as produções surdas têm capacidade de transmitir os conhecimentos através da língua de sinais. A expressão "literatura surda", então, é utilizada para caracterizar histórias que apresentam em sua narrativa a questão da identidade e da cultura surda, além da presença da língua de sinais (KARNOPP, 2006). A literatura surda é expressada também na forma de poesia, história de surdos, piadas, literatura, contos, lendas e outras manifestações da cultura. A literatura surda representa as produções dos surdos.

Assim como é difícil fazer um conceito de Literatura em geral, também não há uma definição única para Literatura Surda. Ela envolve representações produzidas por surdos, onde se produzem significados partilhados em forma de discurso - sem eles, não há representação surda. Os significados são modificados dentro do círculo da cultura e o sujeito não cria sozinho a 
cultura, já que sempre há o coletivo produzindo significados (MOURÃO, 2011, p. 2).

A literatura surda, além de cumprir seu papel dentro da arte - o prazer da leitura -, pode ser utilizada como um recurso importante para a Educação de Surdos, ocupando um espaço fundamental para a construção de identidades surdas, juntamente com outros artefatos culturais que remetem à experiência visual.

\section{Trabalhando com a literatura surda em sala de aula}

Para trabalhar literatura surda com sujeitos surdos, é necessário pensar e repensar a visualidade. O processo de aquisição da linguagem para os surdos exige cuidados. Primeiramente é preciso pensar na principal característica dos sujeitos surdos, a experiência visual. Vale reforçar que a língua de sinais é uma língua de modalidade visual e espacial. $\mathrm{O}$ desenvolvimento da língua de sinais e do português escrito, em uma perspectiva bilíngue, traz muitos benefícios aos alunos surdos se as atividades forem apresentadas para eles na modalidade visual. Além da experiência visual, é de grande importância trazer a discussão sobre identidade para continuar o presente artigo. A literatura surda auxilia os surdos a se conhecerem e a se encontrarem também, a fim de entenderem o mundo surdo e olharem para si mesmos. Antigamente pensávamos que só havia uma única identidade surda, fixa e imutável, relacionada àquela pessoa que não ouve e se comunica em Libras. Mas as identidades surdas são instáveis e nunca serão fixas, pois estão sempre sendo produzidas (PERLIN, 1998).

Identidades não são simplesmente dadas, são construídas em disputas de poder e de resistência no interior das comunidades surdas e permeadas pela visão de mundo do sujeito surdo. As identidades possuem estreita vinculação com a cultura. A inserção em um grupo cultural forja em seus membros identidades semelhantes que são construídas através dos significados que esse grupo dá ao mundo. Dessa forma, a comunidade surda e a escola são os lugares onde são construídas as identidades surdas, uma vez que a grande maioria das crianças surdas é filha de ouvintes. Hoje temos várias publicações científicas sobre identidades surdas, como a da autora surda Emiliana Faria Rosa, que explica a importância da identidade na comunidade surda.

Sim, a identidade surda será aprendida e apreendida no grupo de surdos, no meio, pela troca com o outro. Porém, relevante ressaltar que não há identidade pura, única, como se somente houvesse uma única maneira de viver do surdo. A identidade surda pode ser definida como um conjunto de caraterísticas da comunidade surda. Um conjunto de tradições, costumes, interesses, cultura e língua desenvolvido e vivido pelo povo surdo [...] (ROSA, 2012, p. 22).

A literatura surda traz a possibilidade de o surdo entender o seu mundo e entender quem é e quem são os seus iguais. Os estudos literários do campo de educação de surdos podem colaborar com a construção da identidade do surdo, que tem a oportunidade de descobrir valores da comunidade surda e também a percepção do próprio ser. Além de colaborar com construção da identidade surda, a literatura surda ajuda as pessoas ouvintes a entenderem o mundo surdo de alguma forma.

$\mathrm{Na}$ educação de surdos é fundamental trabalhar com recursos visuais, pois por meio deles é possível adaptar os aspectos culturais nas atividades da literatura surda, como por exemplo, as adaptações de histórias infantis clássicas. Vale trazer algumas adaptações de 
livros feitas por profissionais da área de Educação de Surdos, como Cinderela surda (HESSEL; ROSA; KARNOPP, 2003), Patinho surdo (ROSA; KARNOPP, 2005) e Rapunzel surda (SILVEIRA; ROSA; KARNOPP, 2003). Esses três livros são adaptações dos clássicos da literatura infantil com o objetivo de contribuir para as crianças surdas entenderem a cultura surda, a Libras e as vivências dos sujeitos surdos. Os livros contêm as estruturas de três formas: ilustração/desenho, Libras (escrita da língua de sinais) e português. Os desenhos são importantes para as crianças terem mais facilidade para entender a história do livro.

O livro é importante para todos aprenderem e estudarem, pois tem papel importante no contato das crianças com os mesmos. As crianças surdas desenvolvem aprendizagens através da leitura e da experiência visual, porém sozinhas não têm poder de se formar como leitoras e de serem também leitores visuais - necessitam do livro, de textos e de imagens para que possam desenvolver sua capacidade visual e de leitura. As crianças precisam encontrar significados que ultrapassem o sentido da leitura escolar e, preferencialmente, devem trazer de casa uma relação afetiva com os livros, construída com a família através da LIBRAS (Língua Brasileira de Sinais). (ROSA, 2006, p. 59).

Além de adaptações, temos livros de literatura surda com histórias inéditas e elaboradas por surdos. Em 2001 foi publicado o primeiro livro de literatura surda não adaptada, intitulado Tibi e Joca ${ }^{2}$, escrito pela psicóloga Claúdia Bisol, da Universidade de Caxias do Sul/RS, com a participação especial de um surdo, Tibiriçá Maineri. Na apresentação do livro Tibi e Joca a autora diz: "Esta história de um menino surdo é parecida com a de muitas outras crianças que nasceram ou ficaram surdas. Dúvidas, desespero, culpa, acusações, sofrem os pais. Solidão, um imenso sem-sentido, um mundo que teima em não se organizar, sobre a criança. O que fazer?” (BISOL, 2001). O livro tem 40 páginas e é rico em ilustrações coloridas e, além da história registrada na língua portuguesa, há um boneco que traduz em Libras um resumo de cada página, o que permite ao usuário de Libras acompanhar a história. Esse livro traz a história vivida por muitos surdos que nasceram em famílias de ouvintes que não sabiam se comunicar com o filho surdo e, por isso, é um material importantíssimo para a Educação de Surdos.

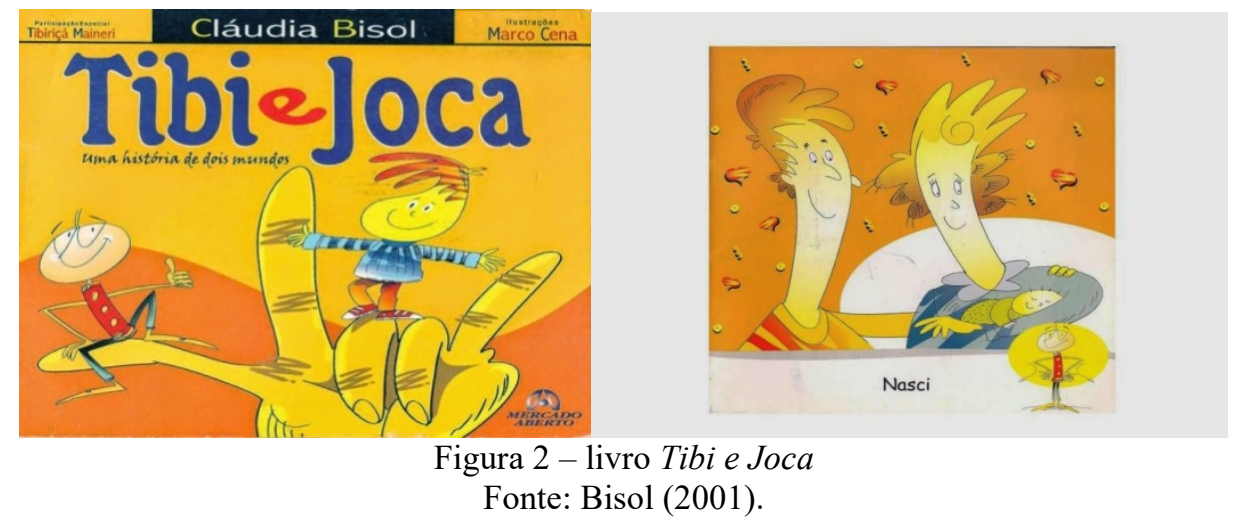

Outro livro de literatura surda não adaptada é O Feijãozinho surdo, de Liége Gemelli Kuchenbecker. Esse livro traz a história de um feijãozinho surdo e de sua família ouvinte, que procura uma escola ideal para ele. Publicado em 2009, tem a Escrita da Língua de Sinais ${ }^{3}$,

\footnotetext{
${ }^{2}$ Livro completo exibido no YouTube ao público. Disponível em:

$<$ https://www.youtube.com/watch?v=1SaHV_Tt-HI $\rightarrow$.

3 Sign writing, o sistema de escrita de sinais iniciado em 1974 por Valerie Sutton.
} 
Português e Libras e foi gravado em DVD pela professora surda Erika Vanessa de Lima Silva. O DVD está anexado ao livro. Esse livro foi criado depois de a autora Liége perceber a contribuição dessa história aos alunos surdos. Ambas as publicações falam de fatos possíveis de serem vivenciados pelos sujeitos surdos e isso contribui para a construção das identidades surdas.

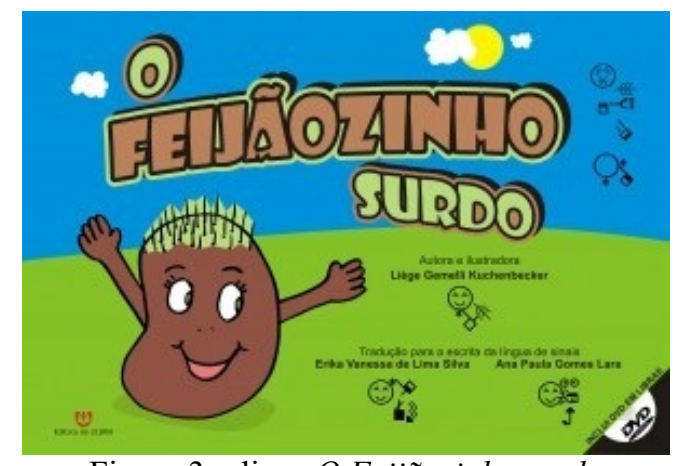

Figura 3 - livro O Feijãozinho surdo Fonte: Kuchenbecker (2009).

Voltando a falar sobre a experiência visual, a principal contribuição da literatura surda para os alunos surdos se articula com a pedagogia visual, que se refere ao ensino pensado por meio de recursos visuais. Para isso teremos que aprofundar o que os Estudos Surdos e as pesquisas nesta área têm compilado sobre a pedagogia visual na educação de surdos. Esse tema foi explorado a partir da semiótica imagética (CAMPELLO, 2008), que é a área de conhecimento que faz uso da língua de sinais e de signos visuais a partir do corpo e do espaço em que flui a corporeidade da língua em sua mais profunda dimensão visual, ou seja, negociar sentidos que se revelam no corpo-língua. Portanto, a semiótica imagética compõe um campo da imagem, da incorporação no ensino de imagens que se configuram no corpo e fazem parte da estrutura da língua de sinais e, por conta disso, deve ser usada como forma de conhecimento linguístico. É importante entender a semiótica imagética para poder trabalhar com a literatura surda, pois sem o artefato visual não é possível haver uma literatura apropriada para os alunos surdos.

Não são somente os livros que fazem parte da literatura surda, temos outras produções que são associadas com a arte, como peças teatrais, piadas, fábulas, poesias, poemas, contação de histórias e produções de vídeos caseiros por sujeitos surdos e ouvintes usuários de Libras (LOPES, 2007). Essas manifestações artísticas são de grande importância para os alunos surdos porque são produzidas utilizando recursos visuais.

A literatura surda tem grande importância na educação de surdos, pois fortalece o campo linguístico da Libras, fazendo com que os alunos utilizem a Libras de uma forma mais espontânea. Um dos aspectos linguísticos da Libras, muito importante na arte, é a expressão facial e corporal, então, dessa forma, o surdo aprende. A literatura surda beneficia os alunos surdos por estabelecer um conhecimento maior da própria língua do sujeito surdo.

\section{Recursos visuais na educação de surdos}

Nos tempos atuais o uso de tecnologia é imenso, ainda mais em se tratando de recursos visuais. Assim, o trabalho com a literatura surda é mais eficaz por dispormos de novas tecnologias, que estão cada vez mais presentes na Educação de Surdos e na vida de cada sujeito surdo. Os surdos produzem várias obras literárias através de vídeos e depois as postam no YouTube, o site de compartilhamento de vídeos enviados pelos usuários na 
internet. Temos traduções também - a Editora Arara Azul publicou uma coleção em CD-R com tradução para Libras de obras literatura clássica. Os clássicos traduzidos são Alice no País das Maravilhas (CARROL, 2002), As aventuras de Pinóquio (COLLODI, 2003) e a história de Aladim e a lâmpada maravilhosa (ALADIM..., 2004). As obras produzidas pelos surdos e ouvintes muito importantes para a cultura surda. Tais livros são fundamentais para os surdos, pois trazem muitos aspectos da cultura surda para circular nas escolas de surdos. Coloco um testemunho de uma surda francesa sobre o livro:

Um livro vai em todo lugar, passa de mão em mão, de espírito em espírito, para deixar sempre uma marca. Um livro é um meio de comunicação raramente dado aos surdos. [...] Vai me permitir dizer aquilo que sempre silenciei, tanto aos surdos como aos ouvintes. (LABORIT, 1994, p. 9).

Antigamente havia pouco contato dos sujeitos surdos com o mundo dos livros por falta de incentivo das escolas e das famílias. Mas hoje a Educação de Surdos está bem mais preparada e a literatura surda pode ser trabalhada com os alunos, mas sempre utilizando recursos visuais. Além dos livros, estão espalhados vários vídeos de piadas, fábulas e poesias produzidos pelos surdos nas redes sociais. Hoje em dia, algumas escolas de surdos disponibilizam vídeos de literatura surda produzidos pelos alunos surdos no Facebook com o objetivo de divulgar a cultura surda na sociedade. Os canais do YouTube de surdos são muito compartilhados pelos surdos.

Existem alguns sites que oferecem recursos que podem colaborar na Educação de surdos com ênfase na literatura surda. No site http://www.lsbvideo.com.br/ é possível encontrar algumas contribuições da literatura surda para serem trabalhadas na escola, como os CD/DVD traduzidos para a Libras em que são explorados os artefatos visuais e a linguística da Libras. Há as fábulas: As aventuras de Pinóquio em LSB e Seis Fábulas de Esopo em LSB, esses vídeos são bem famosos e muito compartilhados por alunos surdos e ouvintes. Hoje, os profissionais das escolas utilizam muito recursos visuais feitos por surdos e ouvintes usuários de Libras, a fim de proporcionar um entendimento maior para os alunos e as contribuições da literatura surda são muito importantes nesse processo.

Em 2006 se deu o início do único curso de graduação voltado à Libras, o Letras/Libras. A Universidade Federal de Santa Catarina (UFSC) é responsável pela iniciativa do projeto desse curso na modalidade da educação a distância, em parceria com a Federação Nacional de Educação e Integração dos Surdos (FENEIS) e o Centro Federal de Educação Tecnológica de Santa Catarina (CEFET/SC). Esse curso trouxe a possibilidade de um crescimento de materiais de literatura surda, o que facilitou o ensino de cultura surda aos alunos surdos. No mesmo curso é ofertada a disciplina literatura surda com o objetivo de preparar os profissionais para trabalhar com os surdos. Ainda há uma carência de materiais, pois sabemos que são produzidos com ênfase na visualidade e, com isso, o valor fica alto, muitas vezes impossibilitando as publicações, como afirma a autora surda Ana Regina e Souza Campello, na sua tese de doutorado sobre a visualidade dos surdos na educação de surdos.

Existe pouca pesquisa voltada à Literatura Surda e existem alguns sites que vendem em caráter particular os CDs e DVDs da literatura infantil e de outros gêneros, mas, mesmo assim, são poucos para a demanda das crianças Surdas no Brasil. Estes materiais são de suma importância para a construção de uma auto-representação e de auto-afirmação da identidade, cultura e língua dos Surdos. Os materiais didáticos também estão no mesmo patamar, ou seja, há insuficiente número de publicações. (CAMPELLO, 2008, p. 138). 
Há surdos e ouvintes que financiam a publicação de suas próprias produções por entender que as escolas que trabalham com alunos surdos precisam muito de materiais visuais para poder transmitir a literatura surda aos alunos. Além dos materiais visuais é fundamental ter professores surdos profissionais para trabalhar a literatura surda, porque tal trabalho exige um conhecimento profundo sobre a cultura surda que deve ser incorporado aos alunos surdos. Com a presença de professores surdos esses alunos podem ter acesso às performances visuais, que são as expressões faciais e corporais.

A maior contribuição para um aluno na aula de literatura surda é a construção da identidade, pois muitos dos livros produzidos por surdos mostram às crianças experiências comuns entre os surdos, em especial a dificuldade de comunicação com os familiares ouvintes. Há uma grande diversidade de recursos visuais para ensino de literatura surda ser mais acessível e eficaz. Com as atividades de literatura surda o aluno surdo aprende várias coisas ao mesmo tempo: cultura surda, identidade e literatura. $\mathrm{O}$ aluno começa a entender que é possível produzir obras com as suas ideias por meio da Libras, a sua primeira língua. A experiência de viver do sujeito visual em contato com duas ou mais línguas traz a possibilidade de um aprendizado maior e articulado com a cultura surda. A maioria dos livros conta com a participação de surdos autores/ilustradores por entenderem bem a cultura surda, o que contribui para a divulgação dessa cultura. Voltando sobre a contribuição de identidade ao aluno surdo, o livro Patinho surdo, de Rosa e Karnopp (2005), as ilustrações deste livro mostram aos alunos surdos que o pato surdo é feliz quando tem acesso à primeira língua desde cedo, e assim os alunos surdos têm a oportunidade de entender a importância da sua primeira língua. Um patinho surdo encontra a sua família surda, comunicando-se em Libras, é um encontro de identidades. Na comunidade surda, não importa se é família de sangue, importa muito se nesse espaço há um, dois ou mais usuários de Libras, assim o surdo se encontra e entende o seu mundo. Dessa forma, a literatura surda colabora de alguma forma, mostrando as obras aos alunos para se encontrarem e conhecerem a identidade surda. Outro exemplo, o livro $O$ Feijãozinho surdo mostra a importância da escola bilíngue para o surdo, isso pode colaborar para a sociedade entender que o surdo precisa da escola bilíngue, uma contribuição importante.

A produção de literatura surda no Brasil expandiu-se depois de 2000 e é fundamental o registro de histórias, pois pode proporcionar, principalmente às escolas, um material com a base na cultura surda. $\mathrm{O}$ registro de histórias contadas por sujeitos que vivenciam experiências visuais é necessário e relevante. Infelizmente é raro encontrar obras dos surdos antigos, as gerações antigas não registravam. Há histórias e contos de literatura surda que são contadas por gerações, há carência em registros. Felizmente hoje, na contemporaneidade, é possível encontrar e explorar os registros armazenados na internet, a principal ferramenta de produções artísticas realizadas em Libras. Muitos surdos postam as suas obras literárias nas redes sociais no dia do surdo e são espalhados diversos vídeos feitos pelos usuários de Libras, com objetivo de agradecer às pessoas do passado que ajudaram a erguer a primeira escola para surdos do Brasil, que foi aberta exatamente no dia 26 de setembro, quando é celebrado o Dia dos Surdos.

\section{Considerações finais}

Eu tive a oportunidade de estudar na escola de surdos com profissionais que sabiam adaptar as obras literárias para Libras e hoje vejo que isso foi muito importante para me oferecer um entendimento maior sobre a cultura surda, além de colaborar na construção da minha identidade, afinal eu sou surda, sendo Libras minha primeira língua. E sou docente, noto a importância de alunos surdos aprenderem a literatura surda, só que é preciso de muita 
adaptação porque a temática é complexa. As aulas práticas também são muito importantes para os alunos surdos, pois montar peças de teatro colabora com um aprendizado maior em vários campos do conhecimento. Por exemplo, na disciplina de história do Brasil, os alunos surdos, junto ao professor, podem montar uma peça de teatro sobre um determinado episódio histórico. Produzir vídeos durante as aulas também é importante e hoje em dia, eles podem ser feitos utilizando telefones celulares. Os órgãos públicos distribuem materiais didáticos às escolas, só que a maioria não vem com adaptação para ensinar aos surdos, por isso é importante pensar e repensar que trabalhar com a literatura surda pede uma atenção no ensino e utilizar certos recursos que auxiliam um aprendizado maior.

Sabemos que os surdos têm grande dificuldade em entender a abstração, então é necessário trabalhar muito com recursos visuais para que os alunos possam imaginar histórias, piadas ou fábulas com temas abstratos. Não é que os surdos não sejam capazes de entender abstrações, mas tais conceitos devem ser trabalhados a partir da experiência visual a fim de que os surdos possam entender melhor. Há muitas poesias que são difíceis de entender, mas trabalhando com artefatos visuais e com a Libras, certamente os surdos terão um aprendizado melhor. Se os trabalhos forem efetuados a partir de artefatos visuais e culturais, serão de grande contribuição para a educação de surdos. O maior resultado de uma educação eficiente é quando o profissional consegue adaptar os materiais didáticos, de português para Libras no caso de alunos surdos e com muita visualidade para que as contribuições sejam grandes. A demanda dos alunos surdos é a qualidade, precisam de professores qualificados que saibam trabalhar com a cultura surda, entender que a visualidade é extremante importante e materiais de qualidade com riqueza de língua de sinais. Também é importante ter um conjunto suficiente para poder produzir as obras como os vídeos para colocar na internet e ser explorado, ou vídeos para ensino.

Atualmente os movimentos surdos lutam pelas manutenção e implementação de escolas bilíngues para surdos, com isso é possível investir na literatura surda. As lutas começaram em 2011, houve uma passeata com mais de quatro mil pessoas e houve uma negociação de literatura surda no movimento com peças de teatros com atores surdos e foram exibidos vários vídeos de poesias pelos surdos em apoio às escolas bilíngues para surdos. Em seguida, houve uma amostra de imagem do vídeo de poesia por Wilson Santos, surdo, a poesia é sobre escolas bilíngues para surdos e a esperança. O vídeo de Santos está disponível no YouTube na forma público e é visível a importância da exploração de materiais produzidos pelos sujeitos surdos para auxiliar um entendimento maior sobre a literatura surda. Os materiais similares deste vídeo de poesia servem como atividades de literatura surda aos alunos surdos, inclusive aos alunos ouvintes. 


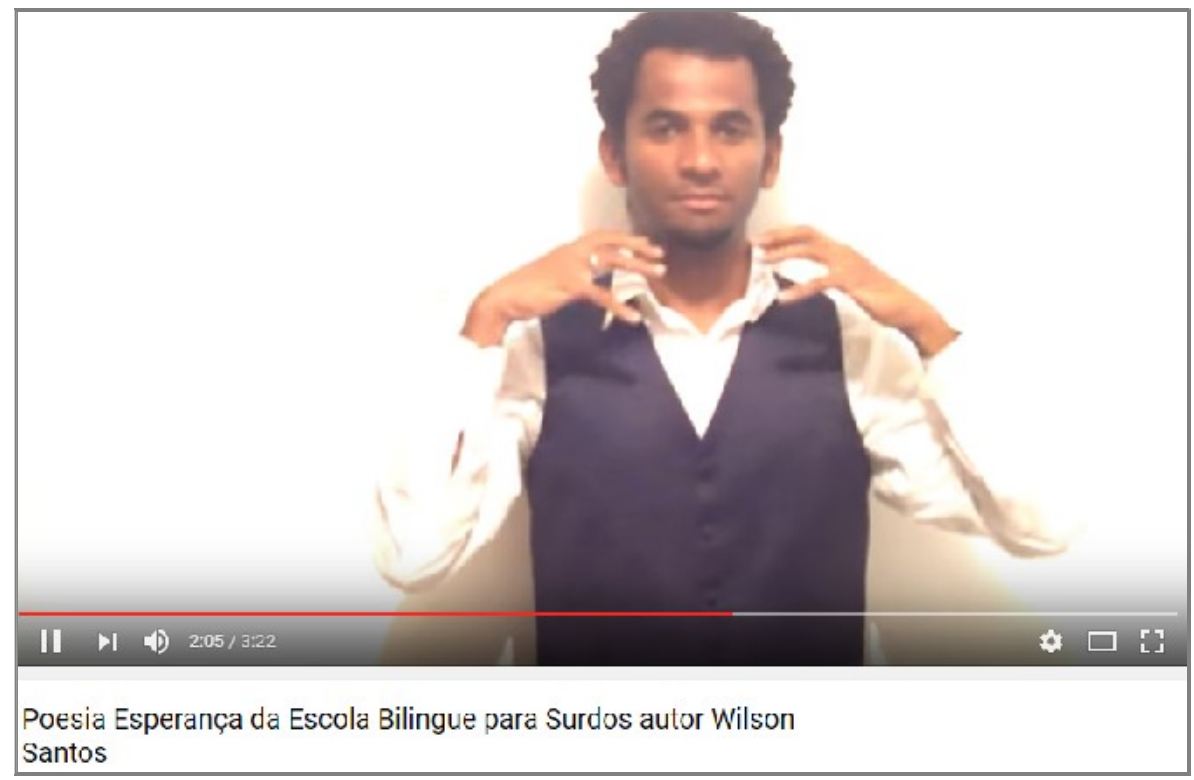

Figura 4 - Vídeo disponível no YouTube Fonte: Santos (2013).

Ainda sobre a negociação de literatura surda com as reivindicações do movimento surdo, tivemos como objetivo mostrar que o ensino para alunos surdos deve ser pensado sempre na primeira língua deles, a língua de sinais, ou seja, Libras, para alunos brasileiros. Mas na contramão desses movimentos estão as políticas de inclusão, que pretendem colocar todos os surdos em escolas regulares. Portanto, é muito importante que os professores se qualifiquem para trabalhar com recursos visuais com os alunos surdos, seja em turmas exclusivas de surdos ou mesmo na inclusão. Para ensinar literatura surda é preciso saber como adaptar, como trabalhar com os livros ou vídeos, assim os alunos terão acesso a essa forma de arte. $\mathrm{O}$ trabalho com a literatura surda deve utilizar a visualidade articulada sempre à tecnologia. A tecnologia certamente revoluciona o ensino e torna o aprendizado com uma qualidade maior. É fundamental saber o uso do ambiente linguístico para que as produções promovam contribuições aos alunos surdos, o ambiente tem que ser em Libras, com um entendimento claro sobre a cultura surda e o uso de Libras adequadamente.

\section{Referências}

ALADIM e a lâmpada maravilhosa. Tradução em Libras de Ana Regina Campello e Nelson Pimenta. Petrópolis/RJ: Arara Azul, 2004. Disponível em: <http://editora-araraazul.com.br/site/produtos/detalhes/60>. Acesso em: 23 nov. 2016.

BAUMAN, Z. Comunidade. Rio de Janeiro: Jorge Zahar, 2003.

BISOL, C. Tibi e Joca: uma história de dois mundos. Porto Alegre: Mercado Aberto, 2001.

CAMPELlO, A. R. S. Aspectos da visualidade na educação de surdos. Florianópolis, 2008. 245f. Tese (Doutorado em Educação) - Programa de Pós-graduação em Educação. Universidade Federal de Santa Catarina - UFSC.

CARROL, L. País das Maravilhas. Londres, Reino Unido: Macmillam, 2002. 
COLLODI, C. Aventuras de Pinóquio. Lisboa, Portugal: Porto, 2003.

FORMOZO, D. Currículo e educação de surdos. Pelotas, 2008. 159f. Dissertação (Mestrado em Educação). Programa de Pós-Graduação em Educação - Universidade Federal de Pelotas.

GAMA, F. J. Iconographia dos signaes dos surdos-mudos. 2011. Disponível em: $<$ http://editora-arara-azul.com.br/site/tribunalivre>. Acesso em: 20 nov. 2016.

GOMES, A. P. G. O imperativo da cultura surda no plano conceitual: emergência, preservação e estratégias nos enunciados discursivos. Santa Maria/RS, 2011. 103f. Dissertação (Mestrado em Educação) - Centro de Educação, Programa de Pós-Graduação em Educação, Universidade Federal de Santa Maria.

HESSEL, C. H.; ROSA, F.; KARNOPP, L. B. Cinderela surda. Canoas: ULBRA, 2003.

KARNOPP, L. B. Literatura surda. Literatura, letramento e práticas educacionais: Grupo de Estudos Surdos e Educação. ETD - Educação Temática Digital. Campinas, v. 7, n. 2, p. 98109, jun. 2006.

KARNOPP, L. B.; KLEIN, M.; LUNARDI-LAZZARIN, M. L. Produções, circulação e consumo da cultura surda brasileira. In: (Orgs.). Cultura surda na contemporaneidade: negociações, intercorrências e provocações. Canoas: Ulbra, 2011. p. 1528.

KUCHENBECKER, L. G. O feijãozinho surdo. Canoas: Ulbra, 2009.

LABORIT, E. O vôo da gaivota. São Paulo: Best Seller, 1994.

LOPES, M. C. Surdez \& educação. Belo Horizonte: Autêntica, 2007.

MOURÃO, C. H. N. Literatura surda: produções culturais de surdos em língua de sinais. In: KARNOPP, L. B.; KLEIN, M.; LUNARDI-LAZZARIN, M. L. (Orgs.). Cultura surda na contemporaneidade: negociações, intercorrências e provocações. Canoas: Ulbra, 2011. p. 7190 .

PERLIN, G. T. T. Identidades surdas. In: SKLIAR, C. A surdez: olhar sobre as diferenças. Porto Alegre: Mediação, 1998. p. 51-73.

PERLIN, G. T. T.; MIRANDA, W. Surdos: o narrar e a política. Ponto de Vista: Revista de Educação e Processos Inclusivos. Florianópolis, n. 5, p. 217-226, 2003.

QUADROS, R. M. de. Educação de surdos: a aquisição da linguagem. Porto Alegre. Artes Médicas, 1997.

QUADROS, R. M. de; MASSUTTI, M. CODAs brasileiros: Libras e Português em zonas de contato. In: QUADROS, R. M. de; PERLIN, G. (Orgs.). Estudos Surdos II. Petrópolis/RJ: Arara Azul, 2007. p. 238-266.

QUADROS, R. M. de; KARNOPP, L. B. Língua de sinais brasileira: estudos linguísticos. Porto Alegre: Artmed, 2004. 
ROSA, E. F. Identidades surdas: o identificar do surdo na sociedade. In: PERLIN, G.; STUMPF, M. (Orgs.). Um olhar sobre nós surdos: leituras contemporâneas. Curitiba: CRV, 2012.

ROSA, F. S. Literatura surda: criação e produção de imagens e textos, 2006. Disponível em: $<$ https://periodicos.sbu.unicamp.br/ojs/index.php/etd/article/view/791>. Acesso em: 23 nov. 2016.

ROSA, F. S.; KARNOPP, L. Patinho surdo. Canoas: Ulbra, 2005.

SACKS, O. W. Vendo vozes: uma viagem ao mundo dos surdos. São Paulo: Companhia das Letras, 2010. Tradução de Laura Teixeira Motta.

SANTOS, W. Poesia esperança da escola bilíngue para surdos, 2013. Disponível em: $<$ https://www.youtube.com/watch?v=b8P8V0BvJlg>. Acesso em: 23 nov. 2016.

SILVEIRA, C. H.; ROSA, F.; KARNOPP, L. B. Rapunzel surda. Canoas: Ulbra, 2003.

STOKOE JR., W. C. Sign language structure: an outline of the visual communication systems of the American deaf. Studies in linguistics, Buffalo, Occasional papers, n. 8, p. 3-37, 1960.

STROBEL, K. As imagens do outro sobre a cultura surda. Florianópolis: UFSC, 2008.

Recebido em: junho de 2017.

Aprovado em: agosto de 2017. 